\title{
Predictors of Depressive Symptoms Among Israeli Jews and Arabs During the Al Aqsa Intifada: A Population-Based Cohort Study
}

\author{
MELISSA TRACY, MPH, STEVAN E. HOBFOLL, PhD, DAPHNA CANETTI-NISIM, PhD, \\ AND SANDRO GALEA, MD, DRPH
}

\begin{abstract}
PURPOSE: We sought to assess the predictors of depressive symptoms in a population-based cohort exposed to ongoing and widespread terrorism.

METHODS: Interviews of a representative sample of adults living in Israel, including both Jews and Arabs, were conducted between August and September 2004, with follow-up interviews taking place between February and April 2005. Censoring weights were estimated to account for differential loss to follow-up. Zero-inflated negative binomial models with bootstrapped confidence intervals were fit to assess predictors of severity of depressive symptoms, assessed using items from the Patient Health Questionnaire. RESULTS: A total of 1613 Israeli residents participated in the baseline interview (80.8\% Jewish, 49.4\% male, mean age 43 years); 840 residents also participated in the follow-up interview. In multivariable models, Israeli Arab ethnicity, lower household income, lower social support, experiencing economic loss from terrorism, experiencing higher levels of psychosocial resource loss, and meeting criteria for post-traumatic stress disorder were significantly associated with increased severity of depressive symptoms. CONCLUSIONS: Material deprivation is the primary modifiable risk factor for depressive symptoms in the context of ongoing terrorism. Efforts to minimize ongoing material and economic stressors may mitigate the mental health consequences of ongoing terrorism.

Ann Epidemiol 2008;18:447-457. (c) 2008 Elsevier Inc. All rights reserved.
\end{abstract}

KEY wORDS: Depression, Terrorism, Post-Traumatic Stress, Disasters, Mass Trauma.

\section{INTRODUCTION}

The Al Aqsa Intifada began in September 2000 ushering in a new wave of terrorism in Israel including suicide bombings in crowded areas and on buses that continues to this day. More than 1000 Israeli residents have been killed and more than 6000 Israeli residents have been injured as a result of the Al Aqsa Intifada (1).

Most studies of mental health among populations experiencing ongoing terrorism have focused on symptoms of posttraumatic stress disorder (PTSD). However, evidence suggests that depressive symptoms also may be increased under conditions of terrorism, as the uncontrollable nature of terrorism may lead to fear and perceptions of loss of control and corresponding feelings of helplessness and hopelessness

From the Department of Epidemiology, University of Michigan School of Public Health, Ann Arbor, MI (M.T., S.G.); Department of Psychology, Kent State University, Kent, OH (S.E.H.); Department of Psychiatry, Summa Health System, Akron, OH (S.E.H.); Department of Political Science, University of Haifa School of Political Science, Haifa, Israel (D.C.); Helen Kellogg Institute of International Studies, University of Notre Dame, Notre Dame, IN (D.C.); and Department of Epidemiology, Columbia University Mailman School of Public Health, New York, NY (S.G.).

Address correspondence to: Sandro Galea MD, DrPH, Department of Epidemiology, University of Michigan School of Public Health, 1214 South University, Room 243, Ann Arbor, MI 48104-2548. Tel.: +1 734647 9741; fax: +1 734998 0006. E-mail: sgalea@umich.edu.

Received August 30, 2007; accepted December 20, 2007.
$(2,3)$. Studies after single instances of terrorism, including the September $11^{\text {th }}$ attacks in New York City, the March $11^{\text {th }}$ train bombings in Madrid, and the Oklahoma City Bombing, have demonstrated a high prevalence of depression, especially among direct victims of the attacks (4-7). In one study of the impact of ongoing terrorism in Israel over half of all respondents reported feeling depressed (8).

There is a paucity of research that has assessed the characteristics and conditions that may influence depressive symptoms in situations of chronic exposure to terrorism. In this study we assessed predictors of depressive symptoms among Israeli residents in order to determine how sociodemographic characteristics, exposure to terrorism, and the consequences of terrorist acts are associated with depressive symptoms in the context of ongoing terrorism.

\section{METHODS}

\section{Participants}

Data were collected through telephone interviews of a cohort of adults (aged 18 years or older) living in Israel. The cohort was recruited through a telephone survey between August 17 and September 8, 2004, using random selection within comprehensive lists based on the Israeli telephone company (Bezeq) database of landline telephone numbers, stratified by region to ensure representation of both Jewish 
Selected Abbreviations and Acronyms

PTSD $=$ post-traumatic stress disorder

$\mathrm{COR}=$ conservation of resources

$\mathrm{PSS}=$ PTSD Symptom Scale

$\mathrm{PHQ}=$ Patient Health Questionnaire

$\mathrm{IPCW}=$ inverse probability of censoring weighted

$\mathrm{IRR}=$ incidence rate ratio

$\mathrm{CI}=$ confidence interval

and Arab Israelis (approximately 98\% of the telephone numbers in Israel are contained in the Bezeq database). Interviews were conducted in Hebrew, Russian, or Arabic by trained interviewers using translated and back-translated questionnaires after oral informed consent was obtained from potential study participants. Each survey was approximately thirty minutes in length. Up to 15 attempts were made to contact each participant. The response rate among those eligible for participation was 39\% overall, although this includes business phones as failed attempts, which would be excluded from attempted numbers in the United States and were responsible for approximately $10 \%$ of failed calls, suggesting a true response rate of $49 \%$. A follow-up interview was conducted between February 22 and April 19, 2005, in which 840 of the 1613 baseline respondents (52.1\%) participated. The Institutional Review Boards of the University of Haifa and Kent State University reviewed and approved the study.

\section{Survey Instrument}

We collected information on the demographic characteristics of respondents, including their ethnicity (Jewish or Israeli Arab), gender, age, educational attainment, marital status, household income, and religiosity (secular, traditional, religious, ultrareligious). Perceived social support was measured with 3 items assessing satisfaction with the social support received from one's spouse/partner, one's family, and one's friends.

We assessed exposure to terrorism and to the consequences of terrorism through a series of questions about participants' experiences since the start of the Al Aqsa Intifada. Participants who reported any of the following were considered to have been directly exposed to terrorism: the death of a family member or friend; injury to themselves, a family member or friend; experiencing a period of time when they did not know but feared someone close to them had been injured or killed in a terror act; witnessing a terror attack or being present at a sight where there were injuries or fatalities as a result of a terror act. Experiencing any threat from terrorism was evaluated through report of any of the following: taking a bus route or going to places that have been targets of attack; having a family member who had taken a bus route or went to places that have been targets of attack; being at a place or on a bus route within 48 hours of a terrorist attack or act of war.

Economic loss related to terrorism was determined through questions assessing property damage and loss of employment as a result of a terror act or war, and level of economic suffering as a result of terrorism and war since the $\mathrm{Al}$ Aqsa Intifada began. Participants who reported experiencing property damage, unemployment, or quite a bit or extreme levels of economic suffering as a result of terrorism were categorized as having experienced economic loss from terrorism.

We used items assessing loss and gain of psychosocial resources that were conceptually derived from Hobfoll's conservation of resources (COR) theory $(9,10)$ and from the COR evaluation (11). The sum of seven items was used to assess loss of psychosocial resources and the sum of 6 items to assess gain in psychosocial resources.

PTSD was assessed with the use of the PTSD Symptom Scale (PSS) (12), which is used to evaluate symptoms that were present for at least 1 month and were related to exposure to terrorism. The PSS has demonstrated high internal consistency $(\alpha=0.86)$ and high agreement with clinician-administered structured interviews assessing PTSD among civilian trauma survivors $(12,13)$. The PSS has also been used to assess post-traumatic stress symptoms among traumatized refugees (14).

Depressive symptoms were assessed using 5 items from the Patient Health Questionnaire (PHQ) (15): "loss of interest or pleasure in all sorts of activities," "feel low, depressed, or hopeless," "difficulties in falling asleep, interrupted sleep, or excess sleeping," "weariness or a lack of energy," and "lack of appetite or excess eating." Respondents were asked to rate the frequency of each item during the two weeks prior to the interview as occurring "not at all," "several days," "more than half the days," or "nearly every day." The sum of these 5 items was calculated (ranging from 0 to 15), with higher scores indicating greater severity of depressive symptoms. The Cronbach's alpha for these 5 items was 0.85 at baseline and 0.83 at follow-up. Depression severity as measured by the total score on the PHQ has been shown to have good validity in both clinical and general population samples, demonstrating high levels of agreement with the Beck Depression Inventory, the General Health Questionnaire, and the Mental Health and Social Functioning dimensions of the Short Form Health Survey $(15,16)$. Only 5 items from the 9-item depression scale of the PHQ were used in this study to preserve the conciseness of the interview and the relevance of the questions to Israeli society; existing work suggests that shortened forms of the PHQ-9 provide valid estimates of depression prevalence and severity (17). Because no cutpoint has been validated for assessing depression when using these 5 items from the PHQ-9, the total depression scale score was used as the primary 
outcome in this analysis. We also created a measure of depression based on a cutpoint of 3 for the PHQ-2, which includes 2 items from the PHQ-9 ("loss of interest or pleasure in all sorts of activities" and "feel low, depressed, or hopeless") with a total score ranging from 0 to 6 (17). A cutpoint of 3 on the PHQ-2 has demonstrated $83 \%$ sensitivity and $92 \%$ specificity for a diagnosis of major depression (17).

\section{Analysis}

Weights were applied to account for oversampling of Israeli Arabs (18). We described the demographic characteristics of the sample at baseline, as well as exposure to terrorism and losses and gains resulting from terrorism. We compared the distributions of baseline characteristics for respondents who did and did not participate in the follow-up survey to assess any differences in those lost to follow-up.

Multivariable models predicting depressive symptoms were fit, including all covariates theorized to influence depressive symptoms and incorporating data from both waves of the survey, accounting for repeated measures on the same individual and using robust standard errors. Because the distribution of the total depression scale score from the five items of the PHQ-9 was highly skewed and similar to that of a count variable, the Poisson distribution was considered for modeling the outcome, rather than the normal distribution. The depression scale score also exhibited overdispersion (i.e., variance greater than the mean, contrary to the assumption of equal mean and variance inherent in the Poisson distribution), as well as more zero values than would be expected under the Poisson distribution (39\% of the depression scale scores were zero), so we also considered using a negative binomial model and zero-inflated models (1921). Likelihood ratio and Vuong tests were used to compare models and select the most appropriate model, which turned out to be a zero-inflated negative binomial model (22). Zeroinflated negative binomial models incorporate 2 separate models: a logistic model evaluating the association between covariates and having a non-zero versus a zero value for the outcome of interest, and a negative binomial model evaluating the association between covariates and a non-zero outcome following the negative binomial distribution (23). We present results as incidence rate ratios, which are calculated by exponentiating the coefficient estimates from the negative binomial model (20) and are interpreted as the risk associated with a particular characteristic relative to a reference group.

To account for the potential effects of differential loss to follow-up on our results, we estimated and applied censoring weights to the models using the inverse probability of censoring weighted (IPCW) approach (24). The probability of participating in the follow-up survey based on all baseline covariates was estimated using a logistic regression model.
The inverse of the probability predicted from this model was used as a censoring weight for each individual. This approach estimates the results that would have been seen in the absence of censoring, assuming that the baseline covariates adequately predict censoring. The true probability of censoring for each individual at the follow-up wave is unknown and, thus, is estimated from a model as described previously. Once an estimated weight has been incorporated into a regression model, confidence intervals must be bootstrapped because no analytical estimate of the standard errors is available. Both the estimation of the censoring weights and the final models applying those weights were bootstrapped in this analysis. For consistency across the final models, all confidence intervals were bootstrapped even when censoring weights were not used.

Finally, we re-ran the final models using a dichotomous measure of depression based on the PHQ-2 as an outcome in order to confirm our results. All analyses were carried out using SAS (SAS Institute, Cary, NC), SUDAAN (RTI International, Research Triangle Park, NC), and Stata (Stata Corporation, College Station, TX).

\section{RESULTS}

Characteristics of the sample at baseline are presented in Table 1 . The majority of the sample $(80.8 \%)$ was Jewish, with the remaining $19.2 \%$ Israeli Arab. More than half $(55.6 \%)$ of the baseline respondents were between the ages of 18 and 44 years old, and $49.4 \%$ were male. The majority $(58.5 \%)$ had more than a high school education and $65.1 \%$ were married. Exposure to actual terror acts or the threat of terrorism was common, with $75.1 \%$ reporting being directly affected by an act of terror or war and $65.7 \%$ experiencing threat from terrorism. Almost a quarter of baseline participants $(23.8 \%)$ suffered economic loss as a result of terrorism or war. The prevalence of PTSD at baseline was $8.9 \%$, and the mean depression scale score in the sample was 3.20 (standard error 0.10, range 0-15). In comparison to those who participated in the follow-up wave, respondents who did not participate in the follow-up wave were younger, less likely to be married, more likely to report a household income below or at the average, and more likely to be religious. However, the application of censoring weights accounted for these differences.

Likelihood ratio tests comparing Poisson and negative binomial models indicated the negative binomial models provided a better fit to the data (log likelihood of a fully adjusted Poisson model was -6017.74 vs. -4619.19 for a negative binomial model; $p<0.0001)$. A Vuong test was used to compare a negative binomial with a zero-inflated negative binomial model, indicating the zero-inflated negative binomial model provided a better fit $(p<0.0001)$. A final 
TABLE 1. Baseline characteristics of all respondents, those who did and did not participate in the follow-up interview, and the censoring-weighted sample

\begin{tabular}{|c|c|c|c|c|c|c|}
\hline & $\begin{array}{c}\text { Total } \\
n=1613\end{array}$ & $\begin{array}{l}\text { Included in } \\
\text { follow-up } \\
n=840\end{array}$ & $\begin{array}{l}\text { Excluded from } \\
\text { follow-up } \\
n=773\end{array}$ & $\begin{array}{c}\text { Censoring- } \\
\text { weighted } \\
\text { sample } n=2453\end{array}$ & $\begin{array}{l}\text { Included vs } \\
\text { Excluded }\end{array}$ & $\begin{array}{l}\text { Total vs } \\
\text { Censoring- } \\
\text { weighted }\end{array}$ \\
\hline & Weighted $\%^{\mathrm{a}}$ & Weighted $\%^{\mathrm{a}}$ & Weighted $\%^{\mathrm{a}}$ & Weighted $\%{ }^{\mathrm{b}}$ & $p$ value $^{c}$ & $p$ value $^{c}$ \\
\hline \multicolumn{7}{|l|}{ Sociodemographics } \\
\hline \multicolumn{7}{|l|}{ Nationality } \\
\hline Jewish & 80.8 & 82.3 & 79.2 & 80.8 & \multirow[t]{2}{*}{0.070} & \multirow[t]{2}{*}{0.973} \\
\hline Israeli Arab & 19.2 & 17.7 & 20.8 & 19.2 & & \\
\hline \multicolumn{7}{|l|}{ Gender } \\
\hline Male & 49.4 & 48.1 & 50.7 & 49.4 & \multirow[t]{2}{*}{0.313} & \multirow[t]{2}{*}{0.934} \\
\hline Female & 50.6 & 51.9 & 49.3 & 50.6 & & \\
\hline \multicolumn{7}{|l|}{ Age, in years } \\
\hline $18-24$ & 15.3 & 12.8 & 18.2 & 15.6 & \multirow[t]{6}{*}{0.007} & \multirow[t]{6}{*}{0.977} \\
\hline $25-34$ & 20.0 & 18.4 & 21.9 & 19.9 & & \\
\hline $35-44$ & 20.3 & 22.0 & 18.4 & 20.1 & & \\
\hline $45-54$ & 18.0 & 19.7 & 16.2 & 17.9 & & \\
\hline $55-64$ & 13.3 & 14.3 & 12.2 & 13.5 & & \\
\hline$\geqslant 65$ & 13.0 & 12.9 & 13.1 & 13.1 & & \\
\hline \multicolumn{7}{|l|}{ Educational attainment } \\
\hline$>$ High school & 58.5 & 59.7 & 57.1 & 58.1 & \multirow[t]{2}{*}{0.318} & \multirow[t]{2}{*}{0.620} \\
\hline$\leqslant$ High school & 41.5 & 40.3 & 42.9 & 41.9 & & \\
\hline \multicolumn{7}{|l|}{ Marital status } \\
\hline Married & 65.1 & 68.2 & 61.6 & 64.9 & \multirow[t]{4}{*}{0.009} & \multirow[t]{4}{*}{0.899} \\
\hline Single/living with partner & 24.4 & 22.5 & 26.5 & 24.6 & & \\
\hline Divorced/separated & 6.0 & 6.1 & 5.8 & 5.8 & & \\
\hline Widowed & 4.6 & 3.2 & 6.1 & 4.7 & & \\
\hline \multicolumn{7}{|l|}{ Household income } \\
\hline Above average & 32.6 & 35.2 & 29.4 & 32.1 & \multirow[t]{2}{*}{0.024} & \multirow[t]{2}{*}{0.482} \\
\hline Below or at average & 67.5 & 64.8 & 70.6 & 67.9 & & \\
\hline Religiosity & & & & & & \\
\hline Secular & 58.1 & 61.3 & 54.6 & 58.0 & 0.036 & 0.983 \\
\hline Traditional & 27.7 & 25.4 & 30.4 & 28.0 & & \\
\hline Religious & 11.0 & 10.0 & 12.2 & 11.0 & & \\
\hline Ultrareligious & 3.1 & 3.4 & 2.8 & 3.1 & & \\
\hline Perceived social support & & & & & & \\
\hline High & 39.6 & 40.2 & 39.0 & 39.3 & 0.581 & 0.879 \\
\hline Medium & 23.3 & 23.9 & 22.6 & 23.3 & & \\
\hline Low & 37.1 & 35.9 & 38.4 & 37.4 & & \\
\hline Exposure to terrorism & & & & & & \\
\hline Any direct exposure to terrori & & & & & & \\
\hline No & 24.9 & 23.4 & 26.6 & 25.1 & 0.143 & 0.789 \\
\hline Yes & 75.1 & 76.6 & 73.4 & 75.0 & & \\
\hline Any threat from terrorism & & & & & & \\
\hline No & 34.3 & 32.1 & 36.6 & 34.4 & 0.062 & 0.802 \\
\hline Yes & 65.7 & 67.9 & 63.4 & 65.6 & & \\
\hline Any economic loss from terro & & & & & & \\
\hline No & 76.2 & 77.8 & 74.4 & 76.2 & 0.125 & 0.996 \\
\hline Yes & 23.8 & 22.2 & 25.6 & 23.8 & & \\
\hline Loss of psychosocial resources & & & & & & \\
\hline Low & 43.5 & 38.7 & 48.8 & 43.4 & $<0.001$ & 0.939 \\
\hline Medium & 37.7 & 39.6 & 35.6 & 37.9 & & \\
\hline High & 18.8 & 21.7 & 15.6 & 18.7 & & \\
\hline Gain of psychosocial resource & & & & & & \\
\hline Low & 37.9 & 36.5 & 39.5 & 38.1 & 0.404 & 0.934 \\
\hline Medium & 27.9 & 29.1 & 26.5 & 27.7 & & \\
\hline High & 34.2 & 34.5 & 34.0 & 34.2 & & \\
\hline
\end{tabular}




\begin{tabular}{|c|c|c|c|c|c|c|}
\hline & $\begin{array}{c}\text { Total } \\
n=1613\end{array}$ & $\begin{array}{l}\text { Included in } \\
\text { follow-up } \\
n=840\end{array}$ & $\begin{array}{l}\text { Excluded from } \\
\text { follow-up } \\
n=773\end{array}$ & $\begin{array}{c}\text { Censoring- } \\
\text { weighted } \\
\text { sample } n=2453\end{array}$ & $\begin{array}{l}\text { Included vs } \\
\text { Excluded }\end{array}$ & $\begin{array}{c}\text { Total vs } \\
\text { Censoring- } \\
\text { weighted }\end{array}$ \\
\hline & Weighted $\%^{\mathrm{a}}$ & Weighted $\%^{\mathrm{a}}$ & Weighted \% ${ }^{\mathrm{a}}$ & Weighted $\%^{\mathrm{b}}$ & $p$ value $^{c}$ & $p$ value $^{c}$ \\
\hline \multicolumn{7}{|l|}{ Psychopathology } \\
\hline \multicolumn{7}{|l|}{ Probable PTSD } \\
\hline No & 91.1 & 91.2 & 90.9 & 91.0 & 0.857 & 0.905 \\
\hline Yes & 8.9 & 8.8 & 9.1 & 9.0 & & \\
\hline Depressive symptoms, mean (SE) & $3.20(0.10)$ & $3.22(0.14)$ & $3.19(0.15)$ & $3.18(0.11)$ & 0.875 & 0.635 \\
\hline
\end{tabular}

${ }^{a}$ Weighted to account for oversampling of Israeli Arabs

${ }^{\mathrm{b} C e n s o r i n g-w e i g h t e d ~ s a m p l e ~ i n c l u d e s ~ a l l ~ b a s e l i n e ~}(n=1613)$ and follow-up $(n=840)$ wave data, with each person-wave serving as a distinct observation

${ }^{c} \mathrm{Chi}$-square $p$-values for all categorical variables; independent sample $t$-test $p$-value for mean depressive symptoms.

likelihood ratio test indicated the zero-inflated negative binomial model provided a better fit than a zero-inflated Poisson model (log likelihood of a fully adjusted zero-inflated Poisson model was -4571.51 vs. -4340.23 for a zero-inflated negative binomial model; $p<0.0001$ ).

Table 2 presents the results of multivariable zero-inflated negative binomial models predicting severity of depression, as measured by the total depression scale score. In a multivariable model controlling for sociodemographic characteristics (Adjusted Model 1; Table 2), among those with a non-zero depression scale score, Israeli Arab ethnicity (incidence rate ratio $[$ IRR] $=1.23,95 \%$ confidence interval $[\mathrm{CI}]=1.11-1.35)$, having average or below-average household income ( $\mathrm{IRR}=1.24,95 \% \mathrm{CI}=1.13-1.38)$, and medium $($ IRR $=1.18,95 \% \mathrm{CI}=1.05-1.33)$ or low $($ IRR $=$ $1.39,95 \% \mathrm{CI}=1.24-1.57$ ) levels of social support (compared to high levels) were associated with increased severity of depressive symptoms. These associations persisted when simultaneously adjusting for measures of exposure to terrorism (Adjusted Model 2) and PTSD (Adjusted Model 3). Additionally, the following characteristics were significantly associated with increased severity of depressive symptoms in the fully adjusted model (Adjusted Model 3): experiencing economic loss from terrorism or war (IRR 1.13, 95\% CI 1.02-1.23), reporting medium or high levels of psychosocial resource loss (compared with low levels of loss, IRR 1.22, 95\% CI 1.09-1.37 for medium levels; IRR 1.48, 95\% CI 1.31-1.67 for high levels), and meeting criteria for PTSD (IRR 1.55, 95\% CI 1.42-1.68). The results of the same models, with censoring weights applied, are presented in $\mathrm{Ta}$ ble 3. There were no substantial differences in the incidence rate ratios calculated from the models with and without censoring weights. We note that the IRRs documented here represent the percent change in the dependent variable (a count measure) for one category of a categorical independent variable relative to the reference category, holding other variables constant. So, for example, an IRR of 1.42 for those with high loss of psychosocial resources means that these persons had a $42 \%$ greater number of depressive symptoms than did those with no loss of psychosocial resources (the referent group).

About one-fifth of respondents (20.9\%) met criteria for depression based on the PHQ-2. There were no substantial differences in the results of multivariable logistic regression models predicting depression based on the PHQ-2, compared with the zero-inflated negative binomial models (results not shown, but available from authors upon request).

\section{DISCUSSION}

In a sample of Israeli residents with high levels of exposure to terrorist acts during the Al Aqsa Intifada, respondents who were Israeli Arabs, had lower income, and lower levels of social support reported greater severity of depressive symptoms. Individuals of lower socioeconomic status and lower social support have been found to be at higher risk of depression after traumatic events in several studies (25-30), perhaps reflecting greater vulnerability of these groups to the consequences of such events. Other studies have also found higher levels of psychological symptoms among ethnic minorities after human-made and natural disasters $(4,31$, 32), which may reflect decreased access to resources and differential reactions to traumatic events in these groups (7, 33). Israeli Arabs may be in a particularly difficult situation, identifying with Arab family members or friends living in the occupied territories while experiencing many of the same terror threats as their Jewish counterparts in Israel as well as potential discrimination because of their Arab ethnicity (34), which may contribute to their greater risk of depressive symptoms.

There is a large body of evidence supporting the association between independent stressful life events, defined as events over which one has no control, and depression (35-39). Greater severity of exposure to war and other traumatic events has been shown to be associated with increasing depressive symptoms $(7,28,40-43)$ and with the persistence of depressive symptoms (44). The prevalence 
TABLE 2. Multivariable zero-inflated negative binomial models predicting severity of depression ${ }^{a}$

\begin{tabular}{|c|c|c|c|c|c|c|}
\hline & \multicolumn{2}{|c|}{ Adjusted model 1} & \multicolumn{2}{|c|}{ Adjusted model 2} & \multicolumn{2}{|c|}{ Adjusted model 3} \\
\hline & $\mathrm{IRR}^{\mathrm{b}}$ & $95 \% \mathrm{CI}^{\mathrm{c}}$ & IRR $^{b}$ & $95 \% \mathrm{CI}^{\mathrm{c}}$ & $\mathrm{IRR}^{\mathrm{b}}$ & $95 \% \mathrm{CI}^{\mathrm{c}}$ \\
\hline \multicolumn{7}{|l|}{ Survey wave } \\
\hline Baseline & 1.00 & - & 1.00 & - & 1.00 & - \\
\hline Follow-up & 1.01 & $0.92-1.11$ & 0.94 & $0.86-1.02$ & 0.97 & $0.89-1.06$ \\
\hline \multicolumn{7}{|l|}{ Sociodemographics } \\
\hline \multicolumn{7}{|l|}{ Nationality } \\
\hline Jewish & 1.00 & - & 1.00 & - & 1.00 & - \\
\hline Israeli Arabs & 1.23 & $1.11-1.35$ & 1.28 & $1.15-1.42$ & 1.21 & $1.10-1.33$ \\
\hline \multicolumn{7}{|l|}{ Gender } \\
\hline Male & 1.00 & - & 1.00 & - & 1.00 & - \\
\hline Female & 1.09 & $1.00-1.19$ & 1.08 & $1.00-1.17$ & 1.06 & $0.98-1.14$ \\
\hline \multicolumn{7}{|l|}{ Age, in years } \\
\hline $18-24$ & 1.00 & - & 1.00 & - & 1.00 & - \\
\hline $25-34$ & 1.02 & $0.88-1.18$ & 1.03 & $0.88-1.19$ & 1.02 & $0.88-1.17$ \\
\hline $35-44$ & 1.19 & $1.02-1.39$ & 1.15 & $0.98-1.33$ & 1.13 & $0.96-1.31$ \\
\hline $45-54$ & 1.07 & $0.90-1.28$ & 1.06 & $0.89-1.25$ & 1.03 & $0.86-1.23$ \\
\hline $55-64$ & 1.02 & $0.83-1.23$ & 1.03 & $0.84-1.22$ & 0.99 & $0.82-1.18$ \\
\hline$\geqslant 65$ & 0.89 & $0.70-1.10$ & 0.94 & $0.76-1.15$ & 0.93 & $0.74-1.13$ \\
\hline \multicolumn{7}{|l|}{ Educational attainment } \\
\hline$>$ High school & 1.00 & - & 1.00 & - & 1.00 & - \\
\hline$\leqslant$ High school & 1.03 & $0.94-1.13$ & 1.05 & $0.96-1.14$ & 1.03 & $0.94-1.12$ \\
\hline \multicolumn{7}{|l|}{ Marital status } \\
\hline Married & 1.00 & - & 1.00 & - & 1.00 & - \\
\hline Single/living with partner & 1.10 & $0.95-1.25$ & 1.13 & $0.98-1.29$ & 1.15 & $1.00-1.31$ \\
\hline Divorced/separated & 0.98 & $0.80-1.16$ & 1.00 & $0.82-1.18$ & 1.02 & $0.85-1.21$ \\
\hline Widowed & 0.85 & $0.68-1.04$ & 0.91 & $0.72-1.15$ & 0.97 & $0.78-1.18$ \\
\hline \multicolumn{7}{|l|}{ Household income } \\
\hline Above average & 1.00 & - & 1.00 & - & 1.00 & - \\
\hline Below or at average & 1.24 & $1.13-1.38$ & 1.20 & $1.08-1.33$ & 1.16 & $1.05-1.28$ \\
\hline \multicolumn{7}{|l|}{ Religiosity } \\
\hline Secular & 1.00 & - & 1.00 & - & 1.00 & - \\
\hline Traditional & 1.09 & $0.98-1.21$ & 1.05 & $0.96-1.16$ & 1.05 & $0.95-1.16$ \\
\hline Religious & 1.07 & $0.94-1.21$ & 1.07 & $0.94-1.20$ & 1.09 & $0.97-1.22$ \\
\hline Ultrareligious & 0.98 & $0.70-1.28$ & 1.05 & $0.75-1.36$ & 1.06 & $0.78-1.38$ \\
\hline \multicolumn{7}{|l|}{ Perceived social support } \\
\hline High & 1.00 & - & 1.00 & - & 1.00 & - \\
\hline Medium & 1.18 & $1.05-1.33$ & 1.13 & $1.00-1.28$ & 1.14 & $1.01-1.27$ \\
\hline Low & 1.39 & $1.24-1.57$ & 1.35 & $1.21-1.50$ & 1.33 & $1.19-1.49$ \\
\hline \multicolumn{7}{|c|}{ Exposure to terrorism } \\
\hline \multicolumn{7}{|c|}{ Any direct exposure to terrorism } \\
\hline No & & & 1.00 & - & 1.00 & - \\
\hline Yes & & & 1.09 & $0.99-1.22$ & 1.08 & $0.98-1.19$ \\
\hline \multicolumn{7}{|l|}{ Any threat from terrorism } \\
\hline No & & & 1.00 & - & 1.00 & - \\
\hline Yes & & & 1.00 & $0.92-1.09$ & 1.00 & $0.91-1.10$ \\
\hline \multicolumn{7}{|c|}{ Any economic loss from terrorism } \\
\hline No & & & 1.00 & - & 1.00 & - \\
\hline Yes & & & 1.18 & $1.06-1.30$ & 1.13 & $1.02-1.23$ \\
\hline Loss of psychosocial resources & & & & & & \\
\hline Low & & & 1.00 & - & 1.00 & - \\
\hline Medium & & & 1.24 & $1.10-1.39$ & 1.22 & $1.09-1.37$ \\
\hline High & & & 1.59 & $1.41-1.79$ & 1.48 & $1.31-1.67$ \\
\hline Gain of psychosocial resource & & & & & & \\
\hline Low & & & 1.00 & - & 1.00 & - \\
\hline Medium & & & 0.96 & $0.86-1.07$ & 0.93 & $0.83-1.03$ \\
\hline High & & & 1.01 & $0.91-1.12$ & 0.96 & $0.87-1.06$ \\
\hline
\end{tabular}


TABLE 2 (continued)

\begin{tabular}{|c|c|c|c|c|c|c|}
\hline & \multicolumn{2}{|c|}{ Adjusted model 1} & \multicolumn{2}{|c|}{ Adjusted model 2} & \multicolumn{2}{|c|}{ Adjusted model 3} \\
\hline & $\mathrm{IRR}^{\mathrm{b}}$ & $95 \% \mathrm{Cl}^{\mathrm{c}}$ & $\mathrm{IRR}^{\mathrm{b}}$ & $95 \% \mathrm{CI}^{\mathrm{c}}$ & $\mathrm{IRR}^{\mathrm{b}}$ & $95 \% \mathrm{CI}^{\mathrm{c}}$ \\
\hline \multicolumn{6}{|c|}{ Psychopathology } & \\
\hline No & & & & & 1.00 & - \\
\hline Yes & & & & & 1.55 & $1.42-1.68$ \\
\hline
\end{tabular}

of depression tends to be greater among direct victims than among those less affected by traumatic events (3, 45). However, in our analysis, direct exposure to terrorism or threat from terrorism was not associated with severity of depressive symptoms in multivariable models controlling for demographic characteristics, losses and gains associated with terrorism, and PTSD. In this sample, exposure to terrorism and the threat of terrorism was high, with the majority of respondents reporting such exposure. It has been suggested that, in situations where exposure to trauma is common, factors other than trauma itself may become more important predictors of psychopathology (29). Our finding of a stronger effect of demographic and other characteristics than direct exposure to terrorism in predicting depressive symptoms may reflect this situation. This explanation is also consistent with another study that found no association between exposure to terrorism in Israel and risk of PTSD or depression (8) and that found a resolution of depressive symptoms despite continuing trauma (46). Another study has shown a stronger relation between nonwarrelated stressors and depression than between objective measures of war-related stressors and depression (47). It is possible that a continuous measure of severity of exposure to terrorism, rather than the dichotomous measure used in this analysis, may provide more insight into the relation between ongoing exposure to terrorism and depressive symptoms. Because information on exposure to terrorist acts was collected several years after the start of the Al Aqsa Intifada, it is also possible that the lack of association between exposure to terrorism and depressive symptoms may be a result of the resolution of depressive symptoms in the years after exposure to these traumatic events.

In our analysis, the material consequences of terrorism were strongly associated with depressive symptoms. In particular, economic loss as a result of terrorism was associated with greater severity of depressive symptoms in adjusted models. The relation between financial hardship and depression has been well-documented in the literature (48-51), and other studies of war and disasters have suggested a relation between financial loss and depression (27, 40, 52). Greater loss of psychosocial resources was also a significant predictor of depressive symptoms in this study, as has been documented in other settings (53). These results demonstrate the potentially important role of economic and other resources in buffering or exacerbating the effects of ongoing terrorism on depression.

Comorbid PTSD and depression are common in populations experiencing traumatic events or ongoing violence (54-57). Some controversy exists about whether comorbidity between PTSD and depression reflects shared pathways between traumatic events and both forms of psychopathology, or whether traumatic events increase the risk of depression independently of their influence on risk of PTSD (54, $58,59)$. In this analysis, we controlled for PTSD to assess the determinants of depressive symptoms independent of the effect of PTSD. We found that the predictors of depressive symptoms were not substantially different when adjusting and not adjusting for PTSD, but PTSD was significantly associated with depressive symptoms, reflecting this comorbid relationship.

This study had several limitations. First, we used an abbreviated, lay-administered measure of depressive symptoms. Assessing depressive symptoms as the key independent variable of interest limits inference about the association between the independent variables and the presence or absence of depression as a categorical disorder. As noted earlier, there is a paucity of evidence about depression after mass traumatic event experiences and the central purpose of this research was to document the correlates of depression in the context of ongoing terrorism. Although our findings were robust across both a measure of severity of depressive symptoms and of depression, these findings ultimately suggest that future research that includes diagnostic measures of depression and that, as such, would permit the estimate of measures of effect for the correlates identified here and depression as a categorical independent variable is warranted. Second, although we included in this assessment the measures that are suspected, based on research in nondisaster 
TABLE 3. Multivariable zero-inflated negative binomial models predicting severity of depression, with censoring weights applied and bootstrapped confidence intervals ${ }^{\mathrm{a}}$

\begin{tabular}{|c|c|c|c|c|c|c|}
\hline & \multicolumn{2}{|c|}{ Adjusted model 1} & \multicolumn{2}{|c|}{ Adjusted model 2} & \multicolumn{2}{|c|}{ Adjusted model 3} \\
\hline & $\mathrm{IRR}^{\mathrm{a}}$ & $95 \% \mathrm{CI}$ & $\mathrm{IRR}^{\mathrm{a}}$ & $95 \% \mathrm{CI}$ & $\mathrm{IRR}^{\mathrm{a}}$ & $95 \% \mathrm{CI}$ \\
\hline \multicolumn{7}{|l|}{ Survey wave } \\
\hline Baseline & 1.00 & - & 1.00 & - & 1.00 & - \\
\hline Follow-up & 0.99 & $0.92-1.07$ & 0.93 & $0.85-1.00$ & 0.96 & $0.88-1.03$ \\
\hline \multicolumn{7}{|l|}{ Sociodemographics } \\
\hline \multicolumn{7}{|l|}{ Nationality } \\
\hline Jewish & 1.00 & - & 1.00 & - & 1.00 & - \\
\hline Israeli Arab & 1.20 & $1.08-1.35$ & 1.24 & $1.12-1.38$ & 1.16 & $1.04-1.29$ \\
\hline \multicolumn{7}{|l|}{ Gender } \\
\hline Male & 1.00 & - & 1.00 & - & 1.00 & - \\
\hline Female & 1.09 & $0.98-1.21$ & 1.08 & $0.99-1.19$ & 1.06 & $0.97-1.16$ \\
\hline \multicolumn{7}{|l|}{ Age, in years } \\
\hline $18-24$ & 1.00 & - & 1.00 & - & 1.00 & - \\
\hline $25-34$ & 1.00 & $0.84-1.19$ & 1.02 & $0.87-1.20$ & 1.00 & $0.85-1.17$ \\
\hline $35-44$ & 1.19 & $0.99-1.43$ & 1.15 & $0.96-1.35$ & 1.12 & $0.94-1.32$ \\
\hline $45-54$ & 1.04 & $0.85-1.29$ & 1.03 & $0.84-1.25$ & 0.99 & $0.82-1.20$ \\
\hline $55-64$ & 1.03 & $0.83-1.29$ & 1.04 & $0.85-1.27$ & 0.99 & $0.81-1.19$ \\
\hline$\geqslant 65$ & 0.87 & $0.68-1.09$ & 0.93 & $0.71-1.14$ & 0.90 & $0.70-1.08$ \\
\hline \multicolumn{7}{|l|}{ Educational attainment } \\
\hline$>$ High school & 1.00 & - & 1.00 & - & 1.00 & - \\
\hline$\leqslant$ High school & 1.01 & $0.91-1.13$ & 1.04 & $0.94-1.14$ & 1.02 & $0.93-1.13$ \\
\hline \multicolumn{7}{|l|}{ Marital status } \\
\hline Married & 1.00 & - & 1.00 & - & 1.00 & - \\
\hline Single/Living with partner & 1.10 & $0.93-1.30$ & 1.12 & $0.95-1.29$ & 1.13 & $0.97-1.30$ \\
\hline Divorced/Separated & 1.02 & $0.82-1.26$ & 1.03 & $0.85-1.27$ & 1.05 & $0.84-1.29$ \\
\hline Widowed & 0.98 & $0.61-1.02$ & 0.82 & $0.63-1.06$ & 0.88 & $0.68-1.13$ \\
\hline \multicolumn{7}{|l|}{ Household income } \\
\hline Above average & 1.00 & - & 1.00 & - & 1.00 & - \\
\hline Below or at average & 1.24 & $1.09-1.40$ & 1.21 & $1.06-1.36$ & 1.18 & $1.04-1.32$ \\
\hline \multicolumn{7}{|l|}{ Religiosity } \\
\hline Secular & 1.00 & - & 1.00 & - & 1.00 & - \\
\hline Traditional & 1.10 & $0.99-1.25$ & 1.07 & $0.96-1.20$ & 1.07 & $0.96-1.19$ \\
\hline Religious & 1.08 & $0.94-1.24$ & 1.07 & $0.93-1.21$ & 1.10 & $0.95-1.26$ \\
\hline Ultrareligious & 1.02 & $0.72-1.39$ & 1.08 & $0.74-1.46$ & 1.09 & $0.77-1.51$ \\
\hline \multicolumn{7}{|l|}{ Perceived social support } \\
\hline High & 1.00 & - & 1.00 & - & 1.00 & - \\
\hline Medium & 1.19 & $1.05-1.36$ & 1.15 & $1.02-1.30$ & 1.15 & $1.01-1.28$ \\
\hline Low & 1.35 & $1.20-1.55$ & 1.32 & $1.17-1.49$ & 1.30 & $1.16-1.47$ \\
\hline \multicolumn{7}{|l|}{ Exposure to terrorism } \\
\hline \multicolumn{7}{|c|}{ Any direct exposure to terrorism } \\
\hline No & & & 1.00 & - & 1.00 & - \\
\hline Yes & & & 1.11 & $0.99-1.23$ & 1.09 & $0.97-1.21$ \\
\hline \multicolumn{7}{|l|}{ Any threat from terrorism } \\
\hline No & & & 1.00 & - & 1.00 & - \\
\hline Yes & & & 0.98 & $0.89-1.08$ & 0.98 & $0.89-1.08$ \\
\hline \multicolumn{7}{|c|}{ Any economic loss from terrorism } \\
\hline No & & & 1.00 & - & 1.00 & - \\
\hline Yes & & & 1.19 & $1.07-1.31$ & 1.14 & $1.03-1.26$ \\
\hline Loss of psychosocial resources & & & & & & \\
\hline Low & & & 1.00 & - & 1.00 & - \\
\hline Medium & & & 1.19 & $1.07-1.36$ & 1.18 & $1.06-1.34$ \\
\hline High & & & 1.52 & $1.37-1.73$ & 1.42 & $1.28-1.62$ \\
\hline Gain of psychosocial resource & & & & & & \\
\hline Low & & & 1.00 & - & 1.00 & - \\
\hline Medium & & & 1.00 & $0.88-1.11$ & 0.97 & $0.86-1.08$ \\
\hline High & & & 1.03 & $0.90-1.13$ & 0.99 & $0.89-1.09$ \\
\hline
\end{tabular}


TABLE 3 (continued)

\begin{tabular}{|c|c|c|c|c|c|c|}
\hline & \multicolumn{2}{|c|}{ Adjusted model 1} & \multicolumn{2}{|c|}{ Adjusted model 2} & \multicolumn{2}{|c|}{ Adjusted model 3} \\
\hline & $\mathrm{IRR}^{\mathrm{a}}$ & $95 \% \mathrm{CI}$ & $\operatorname{IRR}^{\mathrm{a}}$ & $95 \% \mathrm{CI}$ & $\operatorname{IRR}^{\mathrm{a}}$ & $95 \% \mathrm{CI}$ \\
\hline \multicolumn{7}{|c|}{ Psychopathology } \\
\hline \multicolumn{7}{|c|}{ Probable PTSD } \\
\hline $\begin{array}{l}\text { No } \\
\text { Yes }\end{array}$ & & & & & 1.00 & - \\
\hline Yes & & & & & 1.54 & $1.41-1.69$ \\
\hline \multicolumn{7}{|c|}{$\begin{array}{l}\text { aResults of the negative binomial portion of the zero-inflated negative binomial model, fit among those with a non-zero total depression scale score; the same covariates were } \\
\text { significantly associated with having a non-zero depression scale score in the logistic regression portion of the zero-inflated negative binomial models as in the negative binomial } \\
\text { portion, with the following exceptions: female gender was significantly associated with a non-zero depression score in all } 3 \text { adjusted logistic regression models; educational at- } \\
\text { tainment of high school or lower was significantly associated with a non-zero depression score in adjusted model 2; being traditionally religious was associated with a non-zero } \\
\text { depression score in adjusted models } 1 \text { and 2; average or below average household income was not associated with depression in adjusted models } 2 \text { and 3; economic loss was not } \\
\text { associated with depression in adjusted model 3. } \\
\text { 'Incidence rate ratio. } \\
\text { cBootstrapped confidence intervals. }\end{array}$} \\
\hline
\end{tabular}

contexts, to be associated with depression, it is possible that unmeasured confounders accounted for some of the associations documented here. Somewhat mitigating this concern is the observation that all associations documented here are theoretically robust. However, we did not have any information on lifetime history of depression, which is known to be a strong predictor of subsequent depression (37) nor about exposure to trauma prior to the start of the Al Aqsa Intifada or on the exact timing of traumatic events that occurred since the start of the Al Aqsa Intifada. Unfortunately it is always challenging to conduct longitudinal research that includes both pre- and post-terrorism measures, given the unpredictable nature of the mass trauma in question. However, future longitudinal work could improve on this study by assessing timing of ongoing traumatic event experiences and of trajectories of depression hence allowing an assessment of the role of previous depression in determining future depression in the face of ongoing traumatic event experiences. Third, we relied on self-report of exposure to terrorism and the consequences of terrorism. Depressive symptoms may affect the reporting of traumatic events (60); however, we assessed objective exposure to discrete events rather than perceptions of trauma or other subjective measures of past exposure to traumatic events so we do not expect this to have influenced our results. Fourth, we had no information about coping strategies, which may influence the development of psychiatric morbidity in response to ongoing exposure to trauma $(8,61)$. Fifth, the response rate in this survey was $49 \%$. This is comparable, and indeed better, than many other comparable population-based cohort studies (62). In addition, the sample who participated in the study was largely representative of the Israeli adult population after application of weights to account for oversampling of Israeli Arabs (18). Furthermore, despite high loss to follow-up, not surprising in the context of ongoing high intensity conflict, our findings were consistent when accounting for differential loss to follow-up.
These caveats considered, our results suggest a strong relation between ethnic minority status and lower socioeconomic status and depressive symptoms in a sample experiencing high levels of ongoing exposure to terrorism. Although direct exposure to terrorism was not related to depressive symptoms in this sample, the consequences of ongoing terrorism, especially economic and psychosocial resource loss, were particularly salient in influencing depressive symptoms. These findings may suggest important groups to target for interventions aimed at reducing mental health problems in areas experiencing chronic exposure to terror acts like suicide bombings, which have become increasingly prevalent worldwide and have resulted in substantial loss of life and constant threat among civilians in strife-torn areas like the Middle East. In particular, efforts to minimize ongoing material and economic stressors may mitigate the mental health consequences of ongoing terrorism.

This work was funded by grants from the Ohio Board of Regents and the National Institute of Mental Health (MH107687-01A2, Stevan Hobfoll, PI; DA 017642-S1, DA 022720, Sandro Galea, PI). The authors acknowledge the assistance of Dr Jennifer Ahern in implementing the inverse probability of censoring weights and bootstrapping methodologies.

\section{REFERENCES}

1. Israel Ministry of Foreign Affairs. Four years of conflict: Israel's war against terrorism. 2004. Available at: http://www.mfa.gov.il/MFA/Terrorism+ Obstacle + to + Peace/Palestinian + terror + since $+2000 /$ Palestinian + violence + and + terrorism+since+September.htm. Accessed November 30, 2006.

2. Basoglu M, Livanou M, Crnobaric C, Franciskovic T, Suljic E, Duric D, et al. Psychiatric and cognitive effects of war in former Yugoslavia: Association of lack of redress for trauma and posttraumatic stress reactions. JAMA. 2005;294:580-590.

3. Prorokovic A, Cavka M, Cubela Adoric V. Psychosomatic and depressive symptoms in civilians, refugees, and soldiers: 1993-2004 longitudinal study in Croatia. Croat Med J. 2005;46:275-281.

4. North CS, Nixon SJ, Shariat S, Mallonee S, McMillen JC, Spitznagel EL, et al. Psychiatric disorders among survivors of the Oklahoma City bombing. JAMA. 1999;282:755-762. 
5. Galea S, Ahern J, Resnick H, Kilpatrick D, Bucuvalas M, Gold J, et al. Psychological sequelae of the September 11 terrorist attacks in New York City. New Engl J Med. 2002;346:982.

6. Hobfoll SE, Canetti-Nisim D, Johnson RJ. Exposure to terrorism, stressrelated mental health symptoms, and defensive coping among Jews and Arabs in Israel. J Consult Clin Psychol. 2006;74:207-218.

7. Miguel-Tobal JJ, Cano-Vindel A, Gonzalez-Ordi H, Iruarrizaga I, Rudenstine S, Vlahov D, et al. PTSD and depression after the Madrid March 11 train bombings. J Trauma Stress. 2006;19:69-80.

8. Bleich A, Gelkopf M, Solomon Z. Exposure to terrorism, stress-related mental health symptoms, and coping behaviors among a nationally representative sample in Israel. JAMA. 2003;290:612-620.

9. Hobfoll SE. Conservation of resources: A new attempt at conceptualizing stress. Am Psychologist. 1989;44:513-524.

10. Hobfoll SE. Stress, culture, and community: The Psychology and Philosophy of Stress. New York: Plenum; 1998.

11. Hobfoll SE, Lilly R. Resource conservation as a strategy for community psychology. J Community Psychol. 1993;21:128-148.

12. Foa EB, Riggs DS, Dancu CV, Rothbaum BO. Reliability and validity of a brief instrument for assessing posttraumatic stress disorder. J Trauma Stress. 1993;6:459-473.

13. Foa EB, Tolin DF. Comparison of the PTSD Symptom Scale-Interview version and the clinician-administered PTSD scale. J Trauma Stress. 2000;13:181-191.

14. Weine SM, Vojvoda D, Becker DF, McGlashan TH, Hodzic E, Laub D, et al. PTSD symptoms in Bosnian refugees 1 year after resettlement in the United States. Am J Psychiatry. 1998;155:562-564.

15. Kroenke K, Spitzer RL, Williams JB. The PHQ-9: Validity of a brief depression severity measure. J Gen Intern Med. 2001;16:606-613.

16. Martin A, Rief W, Klaiberg A, Braehler E. Validity of the Brief Patient Health Questionnaire Mood Scale (PHQ-9) in the general population. Gen Hosp Psychiatry. 2006;28:71-77.

17. Kroenke K, Spitzer RL, Williams JB. The Patient Health Questionnaire-2: Validity of a two-item depression screener. Med Care. 2003;41:12841292.

18. Byers AL, Allore H, Gill TM, Peduzzi PN. Application of negative binomial modeling for discrete outcomes: A case study in aging research. J Clin Epidemiol. 2003;56:559-564.

19. Long JS. Regression Models for Categorical and Limited Dependent Variables. Thousand Oaks, CA: Sage; 1997.

20. Horton NJ, Kim E, Saitz R. A cautionary note regarding count models of alcohol consumption in randomized controlled trials. BMC Med Res Methodol. 2007;7:9.

21. Vuong Q. Likelihood ratio tests for model selection and non-nested hypotheses. Econometrica. 1989;57:307-333.

22. Afifi AA, Kotlerman JB, Ettner SL, Cowan M. Methods for improving regression analysis for skewed continuous or counted responses. Ann Rev Public Health. 2007;28:95-111.

23. van der Lann MJ, Robins JM. Unified Methods for Censored Longitudinal Data and Causality. New York: Springer; 2003.

24. Farhood L, Zurayk H, Chaya M, Saadeh F, Meshefedjian G, Sidani T. The impact of war on the physical and mental health of the family: The Lebanese experience. Soc Sci Med. 1993;36:1555-1567.

25. Armenian HK, Morikawa M, Melkonian AK, Hovanesian A, Akiskal K, Akiskal HS. Risk factors for depression in the survivors of the 1988 earthquake in Armenia. J Urban Health. 2002;79:373-382.

26. Farhood LF, Noureddine SN. PTSD, depression, and health status in Lebanese civilians exposed to a church explosion. Int J Psychiatry Med. 2003;33:39-53.

27. Scholte WF, Olff M, Ventevogel P, de Vries GJ, Jansveld E, Cardozo BL, et al. Mental health symptoms following war and repression in eastern Afghanistan. JAMA. 2004:292:585-593.
28. Cardozo BL, Bilukha OO, Gotway CA, Wolfe MI, Gerber ML, Anderson M. Report from the CDC: mental health of women in postwar Afghanistan. J Womens Health. 2005;14:285-293.

29. Thapa SB, Hauff E. Psychological distress among displaced persons during an armed conflict in Nepal. Soc Psychiatry Psychiatr Epidemiol. 2005;40:672679.

30. Hobfoll SE, Bridges A, Lomranz J, Eyal N, Tzemach M. Pulse of a nation: Depressive mood reactions of Israelis to the Israel-Lebanon war. J Pers Soc Psychol. 1989;56:1002-1012.

31. Cardozo BL, Bilukha OO, Crawford CA, Shaikh I, Wolfe MI, Gerber ML, et al. Mental health, social functioning, and disability in postwar Afghanistan. JAMA. 2004;292:575-584.

32. Nelson BD, Fernandez WG, Galea S, Sisco S, Dierberg K, Gorgieva GS, et al. War-related psychological sequelae among emergency department patients in the former Republic of Yugoslavia. BMC Med. 2004;2:22.

33. de Jong JT, Komproe IH, Van Ommeren M, El Masri M, Araya M, Khaled $\mathrm{N}$, et al. Lifetime events and posttraumatic stress disorder in 4 postconflict settings. JAMA. 2001;286:555-562.

34. Norris FH, Friedman MJ, Watson PJ, Byrne CM, Diaz E, Kaniasty K. 60,000 disaster victims speak: Part I. An empirical review of the empirical literature, 1981-2001. Psychiatry. 2002;65:207-239.

35. Galea S, Vlahov D, Tracy M, Hoover D, Resnick H, Kilpatrick D. His panic ethnicity and post-traumatic stress disorder after a disaster: Evidence from a general population survey after September 11, 2001. Ann Epidemiol. 2004;14:520-531.

36. Lavi T, Solomon Z. Palestinian youth of the Intifada: PTSD and future orientation. J Am Acad Child Adolesc Psychiatry. 2005;44:1176-1183.

37. Shrout PE, Link BG, Dohrenwend BP, Skodol AE, Stueve A, Mirotznik J. Characterizing life events as risk factors for depression: the role of fateful loss events. J Abnorm Psychol. 1989;98:460-467.

38. Kessler RC. The effects of stressful life events on depression. Annu Rev Psychol. 1997;48:191-214.

39. Kendler KS, Karkowski LM, Prescott CA. Stressful life events and majo depression: risk period, long-term contextual threat, and diagnostic specificity. J Nerv Ment Dis. 1998;186:661-669.

40. Kendler KS, Karkowski LM, Prescott CA. Causal relationship between stressful life events and the onset of major depression. Am J Psychiatry. 1999;156:837-841

41. Maciejewski PK, Prigerson HG, Mazure CM. Self-efficacy as a mediator between stressful life events and depressive symptoms. Differences based on history of prior depression. Br J Psychiatry. 2000;176:373-378

42. Karam EG, Howard DB, Karam AN, Ashkar A, Shaaya M, Melhem N, et al. Major depression and external stressors: The Lebanon Wars. Eur Arch Psychiatry Clin Neurosci. 1998;248:225-230.

43. Mollica RF, McInnes K, Poole C, Tor S. Dose-effect relationships of trauma to symptoms of depression and post-traumatic stress disorder among Cambodian survivors of mass violence. $\mathrm{Br} \mathrm{J}$ Psychiatry. 1998;173:482-488

44. Wilkeson A, Lambert MT, Petty F. Posttraumatic stress disorder, dissocia tion, and trauma exposure in depressed and nondepressed veterans. J Nerv Ment Dis. 2000;188:505-509.

45. Schiff M, Benbenishty R, McKay M, Devoe E, Liu X, Hasin D. Exposure to terrorism and Israeli youths' psychological distress and alcohol use: an exploratory study. Am J Addict. 2006;15:220-226.

46. Tanskanen A, Hintikka J, Honkalampi K, Haatainen K, Koivumaa-Hon kanen $\mathrm{H}$, Viinamaki $\mathrm{H}$. Impact of multiple traumatic experiences on the persistence of depressive symptoms - a population-based study. Nord J Psychiatry. 2004;58:459-464.

47. Goenjian AK, Steinberg AM, Najarian LM, Fairbanks LA, Tashjian M, Pynoos RS. Prospective study of posttraumatic stress, anxiety, and depressive reactions after earthquake and political violence. Am J Psychiatry. 2000;157:911-916. 
48. Bleich A, Gelkopf M, Melamed Y, Solomon Z. Mental health and resiliency following 44 months of terrorism: A survey of an Israeli national representative sample. BMC Med. 2006;4:21.

49. Bryce JW, Walker N, Ghorayeb F, Kanj M. Life experiences, response styles and mental health among mothers and children in Beirut, Lebanon. Soc Sci Med. 1989;28:685-695.

50. Frese M, Mohr G. Prolonged unemployment and depression in older workers: a longitudinal study of intervening variables. Soc Sci Med. 1987;25:173-178.

51. Dooley D, Catalano R, Wilson G. Depression and unemployment: panel findings from the Epidemiologic Catchment Area study. Am J Community Psychol. 1994;22:745-765.

52. Brown GW, Moran PM. Single mothers, poverty and depression. Psychol Med. 1997;27:21-33.

53. Price RH, Choi JN, Vinokur AD. Links in the chain of adversity following job loss: how financial strain and loss of personal control lead to depression, impaired functioning, and poor health. J Occup Health Psychol. 2002; 7:302-312.

54. Hourani LL, Armenian H, Zurayk H, Afifi L. A population-based survey of loss and psychological distress during war. Soc Sci Med. 1986;23:269-275.

55. Hobfoll SE, Tracy M, Galea S. The impact of resource loss and traumatic growth on probable PTSD and depression following terrorist attacks. J Trauma Stress. 2006;19:867-878.
56. Engdahl BE, Speed N, Eberly RE, Schwartz J. Comorbidity of psychiatric disorders and personality profiles of American World War II prisoners of war. J Nerv Ment Dis. 1991;179:181-187.

57. Blanchard EB, Buckley TC, Hickling EJ, Taylor AE. Posttraumatic stress disorder and comorbid major depression: Is the correlation an illusion? J Anxiety Disord. 1998;12:21-37.

58. Erickson DJ, Wolfe J, King DW, King LA, Sharkansky EJ. Posttraumatic stress disorder and depression symptomatology in a sample of Gulf War veterans: A prospective analysis. J Consult Clin Psychol. 2001; 69:41-49.

59. Momartin S, Silove D, Manicavasagar V, Steel Z. Comorbidity of PTSD and depression: associations with trauma exposure, symptom severity and functional impairment in Bosnian refugees resettled in Australia. J Affect Disord. 2004;80:231-238.

60. Shalev AY, Freedman S, Peri T, Brandes D, Sahar T, Orr SP, et al. Prospective study of posttraumatic stress disorder and depression following trauma. Am J Psychiatry. 1998;155:630-637.

61. Breslau N, Davis GC, Peterson EL, Schultz LR. A second look at comorbidity in victims of trauma: the posttraumatic stress disorder-major depression connection. Biol Psychiatry. 2000;48:902-909.

62. Schraedley PK, Turner RJ, Gotlib IH. Stability of retrospective reports in depression: traumatic events, past depressive episodes, and parental psychopathology. J Health Soc Behav. 2002;43:307-316. 